\title{
The aprotinin saga and the risks of conducting meta-analyses on small randomised controlled trials - a critique of a Cochrane review Måns Rosén
}

\author{
Address: SBU (The Swedish Council on Technology Assessment in Health Care), Box 5650, SE-114 86 Stockholm, Sweden
}

Email: Måns Rosén - rosen@sbu.se

Published: 19 February 2009

BMC Health Services Research 2009, 9:34 doi:10.1186/1472-6963-9-34

This article is available from: http://www.biomedcentral.com//472-6963/9/34

Rosén; licensee BioMed Central Ltd.

This is an Open Access article distributed under the terms of the Creative Commons Attribution License (http://creativecommons.org/licenses/by/2.0), which permits unrestricted use, distribution, and reproduction in any medium, provided the original work is properly cited.

Received: 16 September 2008

Accepted: 19 February 2009

\begin{abstract}
Background: Aprotinin for reducing blood loss during coronary artery bypass surgery was withdrawn from the market after early termination of a large randomised controlled trial (RCT) showing excess mortality for patients receiving aprotinin compared to lysine analogues. Several meta-analyses of small RCTs did not show excess mortality and even indicated reduced mortality, while several observational studies showed excess mortality. The aim of this paper is to review the quality of the meta-analysis of a Cochrane report.

Methods: The 52 studies included in the meta-analysis of the Cochrane report were reviewed according to whether an objective to study mortality was formulated in advance, whether followup method or time were specified, and whether the study had statistical power to show any effect.

Results: The Cochrane report restricted the analysis to RCTs, but the largest study should not have been included given that it was a prospective observational study with I 784 patients rather than an RCT. None of the RCTs had sufficient statistical power to detect differences in mortality. Most studies had fewer than 100 patients. Seven out of 5 I RCTs had mortality outcome as one of their objectives. Only very few described follow-up method or time.

Conclusion: It is doubtful whether small studies should be included in meta-analyses if they do not have the purpose of studying the specified outcome and if the follow-up method or time are not adequately described. The aprotinin saga shows overconfidence in small RCTs of inferior quality compared to well-conducted observational studies.
\end{abstract}

\section{Background}

Aprotinin to reduce blood loss during coronary artery bypass surgery was approved by the U.S. Food and Drug Administration (FDA) in 1993 and has been a very common procedure since then. The BART study, which was recently published in the New England Journal of Medicine [1], showed that aprotinin for reducing blood loss during coronary artery bypass surgery increased mortality by 50 percent $(\mathrm{RR}=1.53 ; 95 \% \mathrm{CI}, 1.06-2.22)$ compared with groups receiving lysine analogues. Before BART, several meta-analyses of randomised controlled trials (RCTs) had shown no indication of an excess risk of death or had even shown a reduced risk [2-4], while several observational studies had shown excess mortality risks and increased risk of renal dysfunction [5-9]. The reasons for these discrepancies deserve further analysis.

The focus of the meta-analyses was usually aprotinin's ability to reduce blood loss during surgery. Aprotinin has been a successful treatment in this connection. Based on a 
cumulative meta-analysis of 64 trials, an editorial in The Lancet even claimed that many of the later studies were unnecessary since meta-analysis showed that the effects had already been established after the twelfth trial in 1992 [10]. This was probably true with respect to blood loss, but not with respect to mortality and other adverse effects. Blood loss is also primarily a surrogate endpoint.

The findings of the observational studies by Mangano $[6,7]$, Schneeweiss [8] and Shaw [9] were based on prospective cohorts of 4 374, 78199 and 10275 patients respectively. They all showed statistically significant mortality odds ratios. The study by Mangano [6], which had an odds ratio of 1.48 (95\% CI, 1.19-1.85), controlled for background characteristics such as age, gender, socioeconomic status, geographic region and medical history. The study by Schneeweiss [8] showed an odds ratio of 1.64 (95\% CI, 1.50-1.78) adjusted for 41 background characteristics. Both of these studies showed a dose-response relationship, with higher mortality for higher doses of aprotinin. A case-control study by Karkouti et al used propensity scores and did not find any differences in adverse outcomes except for renal dysfunction, which was significantly higher in the aprotinin group [5].

The observational studies of aprotinin, which were much larger than the RCTs, controlled for many important background characteristics of the patients. The critics of these observational studies emphasised the limitations of observational studies in general, as well as uncertainty about whether all confounders had been controlled for. Selection bias may also have been present due to the fact that aprotinin was a preferred choice for patients with high risk of bleeding. These factors were probably among the main reasons that FDA did not take more forceful action between 2006 and late 2007.

One of the main purposes of meta-analysis is to summarise data from small studies to obtain more robust estimates of effects. However, this is appropriate only if the small RCTs are well-designed and well-conducted. In order to analyse whether this was the case, this author examined all the studies in one of the meta-analyses according to certain quality criteria. The meta-analysis chosen was a 2007 Cochrane report that reviewed antifibrinolytic use for minimising perioperative allogenic blood transfusion [2]. The report included assessments of both the benefits and the risks of aprotinin versus placebo or other treatment options. The review restricted the analysis to RCTs and referred to observational studies in the discussion section only.

Mortality was assessed in the Cochrane report by performing a meta-analysis of 52 small RCTs. The meta-analysis showed no excess risk for aprotinin versus placebo $(R R=$
$0.90,95 \%$ CI, $0.67-1.20$ with a total of 7721 patients and 192 deaths).

\section{Methods}

All 52 studies were analysed in full text. The three questions raised were: Was mortality stated as an objective? Did the study have power to analyse adverse mortality effects? Was the method for follow-up clearly described? If mortality was stated as an objective and if statistical power was considered, it is an indication that the investigators intended to examine mortality thoroughly. A description of the follow-up method is very important if the reader is to have confidence in the results.

\section{Results}

The 52 studies were assessed by analysing the formulated objectives, the specified follow-up method and time, and potential power to detect differences in mortality (Table 1 ). The largest study should not have been included given that it was a prospective observational study with 1784 patients rather than an RCT. Most studies had fewer than 100 patients. Seven out of 51 (13.7\%) RCTs had mortality outcome as one of the objectives. None of the studies had sufficient statistical power to detect differences in mortality. Only very few described the follow-up method. Follow-up time was specified in 16 out of 51 (31.4\%) studies and varied from 24 hours, during hospitalisation, to 30 days to 3 months. Most studies did not show whether mortality was measured during surgery, hospital stay or longer follow-up periods.

\section{Discussion}

The analysis was restricted to RCTs, but the largest of the 52 included studies was an observational study by Dietrich et al [11] and was therefore erroneously included in the meta-analysis. This study was conducted was conducted before the FDA approval in 1993 when there was no suspicion of adverse effects. This is apparent from the study design with no focus on mortality and no control for confounding factors. Analysis of all the included RCTs in the Cochrane review of mortality showed that a minority of the studies had mortality outcome as one of their objectives. Nor did any of the studies have statistical power to detect differences in mortality. This clearly indicates the investigators' lack of focus on mortality and adverse events. However, this does not mean a priori that the studies lacked quality, although it does indicate that less time was spent on this part of the study design.

The fact that most studies completely lacked a description and specification of follow-up method or time should raise more serious concerns. Many studies did not specify whether deaths occurred during surgery, during hospital stay or within a specified period of time. It is questionable whether it is appropriate to perform a meta-analysis with 
Table I: Characteristics of included RCT studies in the Cochrane meta-analysis of adverse mortality effects Aprotinin versus placebo.

\begin{tabular}{|c|c|c|c|c|}
\hline Reference, author & $\begin{array}{l}\text { Adverse-mortality effects } \\
\text { formulated as an outcome } \\
\text { in the objective }\end{array}$ & $\begin{array}{l}\text { Incluc } \\
\text { analy } \\
\mathbf{N}\end{array}$ & $\begin{array}{l}\text { d design or power to } \\
\text { y effects }\end{array}$ & $\begin{array}{l}\text { Method and follow-up } \\
\text { period for studying } \\
\text { adverse mortality effects }\end{array}$ \\
\hline Alvarez, 1995 & No & 100 & No & Not specified \\
\hline Bidstrup, 1989 & No & 80 & No & Not specified \\
\hline Bidstrup, 1993 & No & 90 & No & Not specified, $7-12$ days \\
\hline Blauhut, 1994 & No & 43 & No & Not specified \\
\hline Casas, 1995 & No & 149 & No & Not specified \\
\hline Cosgrove, 1992 & No & 169 & No & Not specified \\
\hline D'Ambra, 1996 & Yes & 212 & No & Yes, hospitalisation \\
\hline Dietrich, 1992 & Yes, but no RCT & 1784 & Yes & Yes, hospitalization \\
\hline Dietrich, 1995 & No & 30 & No & Not stated, at least $4 \mathrm{I}$ days \\
\hline Ehrlich, 1998 & No & 50 & No & Not stated, at least 30 days \\
\hline Garcia-Huete, 1997 & No & 80 & No & Not stated, at least 30 days \\
\hline Green, 1995 & Yes & 84 & No & Yes, 3 months after discharge. \\
\hline Hardy, 1993 & No & 41 & No & Not specified \\
\hline Hayashida, 1997 & Yes & 167 & No & Not stated, at least 12 days \\
\hline Jamieson, 1997 & No & 91 & No & Not specified \\
\hline Lab, 1995 & No & 110 & No & Yes, hospitalisation \\
\hline Lemmer, 1996 & Yes & 704 & No & Not stated \\
\hline Lemmer, 1994 & Yes & 216 & No & Yes, 30 days mortality \\
\hline Levy, 1995 & Yes & 287 & No & Not specified \\
\hline Liu, 1993 & No & 40 & No & Not specified \\
\hline Maccario, $1994[\mathrm{It}]$ & No & 99 & No & Not stated \\
\hline Mohr, 1992 & No & 50 & No & Not specified \\
\hline Okita, 1996 & No & 112 & No & Not specified \\
\hline Rocha, 1994 & No & 109 & No & Yes, first 10 days \\
\hline Royston, 1987 & No & 22 & No & Not specified \\
\hline Stammers, 1997 & No & 20 & No & Yes, hospitalisation \\
\hline Swart, 1994 & Yes & 100 & No & Yes, 7 days after surgery \\
\hline
\end{tabular}


Table I: Characteristics of included RCT studies in the Cochrane meta-analysis of adverse mortality effects Aprotinin versus placebo.

\begin{tabular}{|c|c|c|c|c|}
\hline Ashrat, 1997 & No & 38 & No & Not stated \\
\hline Alderman, 1998 & No & 870 & No & Yes, hospitalisation \\
\hline Bidstrup, 2000 & No & 60 & No & $\begin{array}{l}\text { Not specified, } 15 \text { days } \\
\text { reported }\end{array}$ \\
\hline Cohen, 1998 & Yes, maybe & 115 & No & Not specified \\
\hline Misfeld, 1998 & No & 42 & No & Not specified, hospitalisation \\
\hline Nuttall, 2000 & No & 168 & No & Not specified, 24 hours \\
\hline Schweizer, 2000 & No & 57 & No & Not specified \\
\hline Moran, 2000 & No & 42 & No & Yes, 3 months \\
\hline Murkin, 2000 & No & 298 & No & Yes, 3 months \\
\hline Alvarez, 2001 & No & 55 & No & Not specified \\
\hline Dignan, 200I & No & 202 & No & Not specified \\
\hline Findlay, $200 \mathrm{I}$ & No & 63 & No & Yes, hospitalisation \\
\hline Kyriss, 200I & No & 38 & No & Not specified \\
\hline Golanski, 2000 & No & 54 & No & Not specified \\
\hline Palmer, 2003 & No & 100 & No & Yes, 3 months \\
\hline Englberger, 2002a & No & 29 & No & Yes, hospitalisation \\
\hline Englberger, 2002b & No & 47 & No & Yes, hospitalisation \\
\hline Kipfer, 2003 & No & 30 & No & Not specified \\
\hline Rodrigus, 1996 & No & 93 & No & Not specified \\
\hline Kuepper, 2003 & No & 120 & No & Yes, 24 hours after surgery \\
\hline Van der Linden, 2005 & No & 75 & No & Probably 30 days \\
\hline Kunt, 2005 & No & 86 & No & $\begin{array}{l}\text { Probably I day, operative } \\
\text { deaths }\end{array}$ \\
\hline Koster, 2004 & No & 200 & No & Yes, during hospitalisation \\
\hline Diprose, 2005 & No & 198 & No & Not stated \\
\hline Kuitunen, 2005 & No & 60 & No & Not stated \\
\hline
\end{tabular}

Footnote: The complete references can be found in the Cochrane review by Henry DA et al.[2].

very different follow-up times or when most of the studies did not specify follow-up time at all. Mortality is not an adverse effect that occurs during hospitalisation only. Severe complications may lead to death long after dis- charge from hospital. For example, thrombotic events can manifest clinically over a period of months or years following arterial occlusion $[12,13]$. In order to properly analyse mortality, follow-up time must be specified. 
The results of this paper could contribute to the ongoing debate concerning the value of large versus small trials. Previous studies have suggested that publication bias is one reason for discrepancies between the results of large RCTs and meta-analyses of small RCTs [14-16]. Kjaergard et al [17] focused on methodological quality and concluded that inadequate generation of the allocation sequence, allocation concealment and double blinding lead to exaggerated estimates of benefits and may contribute to discrepancies between the results of large RCTs and meta-analyses of small RCTs. In general, it seems likely that large studies requiring more resources and funds have undergone a more thorough review process than small studies. The results of the present paper also indicate the need to analyse the quality of studies before including them in a meta-analysis. Studies cannot be included if the method of following up outcome has not been specified. Already before the publication of the BART study, an editorial in the New England Journal of Medicine discussed the limitations of these small trials and argued that they should have been interpreted more cautiously, particularly given the contradictory findings of some epidemiological studies [18].

Another issue raised by the aprotinin saga is the value of observational studies in examining rare and adverse outcomes such as mortality. The advantages of large, wellconducted RCTs are undisputable. But even large RCTs rarely have the ability to show significant results concerning rare outcomes and usually have short follow-up periods. In the case of aprotinin, data from several wellconducted and very large observational studies were available between 2006 and late 2007 without any major action being taken. Two of the studies also showed a doseresponse relationship, with higher mortality odds ratios for higher doses of aprotinin [7,8] A 2006 case-control study and a 2007 meta-analysis of RCTs showed that highdose aprotinin significantly increased the risk of renal dysfunction [19]. The main reasons for not taking action seem to be confidence in small RCTs that did not show any adverse effects and mistrust of observational studies that showed excess mortality. In this case, the consistent findings of the observational studies should have been more carefully considered, especially when other measures to reduce bleeding were available. In retrospect, it seems clear that aprotinin would have been withdrawn from the market by the company earlier if FDA and others had taken well-conducted observational studies more seriously.

\section{Conclusion}

The RCTs included in the Cochrane review had blood loss as the main outcome and were not suitable for studying mortality. Methods were not well-specified and had serious limitations. In such cases, meta-analysis is a question- able approach, considering the methodological limitations of such small trials.

\section{Competing interests}

The author declares that they have no competing interests.

\section{Response}

Response by David Henry

Email: david.henry@newcastle.edu.au

Address: University of Newcastle, Faculty of Health, Level 5, Clinical Sciences Building, Newcastle Mater Hospital, Waratah, NSW, Australia, 2298.

Professor Måns Rosén raises concerns about our 2007 Cochrane review of anti-fibrinolytic drugs [2]. The topic is an important one - many patients receive these drugs as an adjunct to reduce blood loss during a variety of surgical procedures. Some of his concerns go to the heart of assumptions that are made when conducting meta-analyses of randomized controlled clinical trials.

First, we should point out that we have updated some of the meta-analyses of trials contained in the Cochrane review and have recently published the results. This analysis is confined to the use of anti-fibrinolytic trials in cardiac surgery. The full text is available at [20]. In the updated report we found an increased risk of death in subjects treated with aprotinin compared with tranexamic acid or aminocaproic acid. Our conclusions were "The risk of death tended to be consistently higher with use of aprotinin than with use of lysine analogues. Aprotinin had no clear advantages to offset these harms...The conclusions of our updated review conflict with those of our published Cochrane review.... The addition of data from the large BART study increased the relative risk of death with the use of aprotinin compared with the use of either tranexamic acid or epsilon aminocaproic acid."

So, the updated review is consistent with the observational studies of aprotinin (recently presented in a systematic review [21]) in finding an increased risk of death with aprotinin compared with the lysine anti-fibrinolytic agents. But significantly, the updated meta-analysis found no increase in the risk of death with aprotinin compared with placebo/no treatment when used in cardiac surgery (summary RR for death $0.93 ; 95 \%$ CI $0.69,1.25$ ). This summary analysis comprised results from forty-nine trials of aprotinin, which included 7439 participants and reported on 182 deaths. This finding troubles Professor Rosén as it is at odds with the results of large observational studies and is based on small randomized trials that were not designed to show a change in the incidence of 
death or indeed cardiovascular events. It should be noted here that neither was the BART study.

The five main criticisms made by Rosén are: that few of the trials had mortality as a stated outcome; none of the trials had statistical power to detect differences in mortality; very few trials described the follow-up methods and follow-up time was not specified in most of them; follow-up may have been too short to quantify late deaths. One large study was not a randomized trial. While we don't dispute the accuracy of these observations about the individual studies we disagree with the inferences that Professor Rosén makes regarding the systematic review.

If at least one large trial had specified thrombosis (a theoretical adverse effect of these drugs) and death as outcomes, and had adequate power and sufficient follow-up, there would have been little need for the meta-analysis. One of the purposes of systematic reviews is to examine events that were not primary outcomes of the individual trials. By denying this Rosén is arguing against a central purpose of systematic reviews. In terms of patient followup, this varied between the aprotinin trials, but should not have varied between the treatment and control arms of the individual trials. In other words, it is unlikely that this was a source of bias either toward or away from the null. While some non-fatal events could lead to late mortality, we found no increase in the risk of non-fatal thrombosis. In addition, the BART trial3, cited by Rosén, found a separation of survival curves early in the post-operative phase and the curves are roughly parallel from Day 10 onwards. So, it is unlikely that undetected late mortality accounts for the lack of risk that we found in the metaanalysis of the placebo/inactive controlled aprotinin trials.

However, we do share one of Rosén's worries, which have also been expressed by Ray [22]. This concerns the completeness of reporting of uncommon events in small clinical trials. We put considerable effort into identifying trials that appeared to report mortality, but we have no way of assessing how rigorously this was done. One concern about trials of drugs is the tradition to report 'adverse reactions' - events that are reported as 'possibly' or 'probably' caused by the drug. The use of causality assessment, traditional in the assessment of voluntary adverse reaction reports, could lead to under-reporting of events. This process has no place in the reporting of the results of clinical trials.

Regarding the alleged inclusion of one non-randomized study in the meta-analysis, the methods section in this study states: "Patients were randomly assigned to either an aprotinin treatment group (group A) or to a control group without aprotinin (group C)". We accepted this informa- tion in good faith, but scored the methodological quality of the study as low. We did not routinely contact study authors to confirm the details of randomization. Like most meta-analysts we accepted and scored the written description of the methods. We subsequently contacted the senior author, Professor Wulf Dietrich of the University of Munich, who kindly reviewed his files (the study was reported in 1992 [11]) and has advised us that in his opinion the study does not meet contemporary standards for being considered 'randomized', that there was a possibility of selection bias, but this would have led to sicker patients receiving aprotinin. It should be noted that exclusion of this study does not change the overall estimate of mortality with aprotinin compared with control: Pooled $\mathrm{RR}=1.02$ (95\% CI 0.71 to 1.47 ).

So did our Cochrane review miss an adverse effect of aprotinin? That is possible. Are there significant problems with meta-analyses of infrequent outcomes measured in small clinical trials? Yes there are. But in our view the major criticisms voiced by Professor Rosén concerning the specification of outcomes, statistical power of individual studies and variable follow up of trial participants are not the key issues. Under-reporting of infrequent events is pivotal and if non-differential (the most likely scenario) will lead to a bias to the null. This could account for the fact that we found no increase in mortality in the aprotinin trials. We have acknowledged this in the updated review. 3 Despite considerable methodological improvements, meta-analysis remains an imperfect science, being an observational not an experimental discipline, which relies heavily on the diligence of trial investigators and authors of reports.

Systematic reviews must be rigorously performed, but Professor Rosén has not made a comprehensive assessment of the quality of our work. Tools exist to enable appraisal of systematic reviews (for instance the recently validated AMSTAR instrument) [23]. Systematic reviews have value in summarizing literature, providing overall estimates of effect and in assisting in the planning of clinical trials. In the latter regard it is significant that two of the authors of the Cochrane review (Fergusson and Laupacis [1]) were involved in the planning conduct and monitoring of the BART trial. This trial owed a lot to the results of the many published meta-analyses of this literature.

\section{Acknowledgements}

The study is funded by the Swedish Council on Technology Assessment in Health Care.

\section{References}

I. Fergusson DA, Hébert PC, Mazer CD, Fremes S, MacAdams C, Murkin JM, Teoh K, Duke PC, Arellano R, Blajchman MA, Bussières JS, Côté D, Karski J, Martineau R, Robblee JA, Rodger M, Wells G, Clinch J, Pretorius R, BART Investigators: A comparison of aprotinin and lysine analogues in high-risk cardiac surgery. N Engl J Med 2008, 358(22):2319-2331. 
2. Henry DA, Carless PA, Moxey AJ, O'Connell D, Stokes BJ, McClelland B, Laupacis A, Fergusson D: Anti-fibrinolytic use for minimising perioperative allogeneic blood transfusion. Cochrane Database Syst Rev 2007:CD001886.

3. Levi M, Cromheecke ME, de Jonge E, Prins MH, de Mol BJ, Briet E, Buller HR: Pharmacological strategies to decrease excessive blood loss in cardiac surgery: a meta-analysis of clinically relevant endpoints. Lancet 1999, 354(9194): 1940-1947.

4. Sedrakyan A, Treasure T, Elefteriades JA: Effect of aprotinin on clinical outcomes in coronary artery bypass graft surgery: a systematic review and meta-analysis of randomized clinical trials. I Thorac Cardiovasc Surg 2004, I 28(3):442-448.

5. Karkouti K, Beattie WS, Dattilo KM, McCluskey SA, Ghannam M, Hamdy A, Wijeysundera DN, Fedorko L, Yau TM: A propensity score case-control comparison of aprotinin and tranexamic acid in high-transfusion-risk cardiac surgery. Transfusion 2006, 46(3):327-338.

6. Mangano DT, Miao Y, Vuylsteke A, Tudor IC, Juneja R, Filipescu D, Hoeft A, Fontes ML, Hillel Z, Ott E, Titov T, Dietzel C, Levin J, Investigators of The Multicenter Study of Perioperative Ischemia Research Group; Ischemia Research and Education Foundation: Mortality associated with aprotinin during 5 years following coronary artery bypass graft surgery. JAMA 2007, 297(5):47|-479.

7. Mangano DT, Tudor IC, Dietzel C: The risk associated with aprotinin in cardiac surgery. N Engl J Med 2006, 354(4):353-365.

8. Schneeweiss S, Seeger JD, Landon J, Walker AM: Aprotinin during coronary-artery bypass grafting and risk of death. $N$ EnglJ Med 2008, 358(8):77|-783.

9. Shaw AD, Stafford-Smith M, White WD, Phillips-Bute B, Swaminathan M, Milano C, Welsby IJ, Aronson S, Mathew JP, Peterson ED, Newman MF: The effect of aprotinin on outcome after coronaryartery bypass grafting. N Engl J Med 2008, 358(8):784-793.

10. Young C, Horton R: Putting clinical trials into context. Lancet 2005, 366(9480): 107-108.

II. Dietrich W, Barankay A, Hahnel C, Richter JA: High-dose aprotinin in cardiac surgery: three years' experience in 1,784 patients. J Cardiothorac Vasc Anesth 1992, 6(3):324-327.

12. Feit F, Brooks MM, Sopko G, Keller NM, Rosen A, Krone R, Berger $\mathrm{PB}$, Shemin R, Attubato MJ, Williams DO, Frye R, Detre KM: Longterm clinical outcome in the Bypass Angioplasty Revascularization Investigation Registry: comparison with the randomized trial. BARI Investigators. Circulation 2000 I 0 I(24):2795-2802.

13. Kaehler J, Koester R, Billmann W, Schroeder C, Rupprecht HJ, Ischinger $T$, Jahns $R$, Vogt A, Lampen M, Hoffmann R, Riessen $R$, Berger J, Meinertz T, Hamm CW: I3-year follow-up of the German angioplasty bypass surgery investigation. Eur Heart $J$ 2005, 26(20):2|48-2।53.

14. Cappelleri JC, loannidis JP, Schmid CH, de Ferranti SD, Aubert M, Chalmers TC, Lau J: Large trials vs meta-analysis of smaller trials: how do their results compare? JAMA 1996, 276(16): 1332-1338

15. loannidis JP, Cappelleri JC, Lau J: Issues in comparisons between meta-analyses and large trials. JAMA 1998, 279(14): 1089-1093.

16. LeLorier J, Gregoire G, Benhaddad A, Lapierre J, Derderian F: Discrepancies between meta-analyses and subsequent large randomized, controlled trials. N Engl J Med 1997, 337(8):536-542.

17. Kjaergard LL, Villumsen J, Gluud C: Reported methodologic quality and discrepancies between large and small randomized trials in meta-analyses. Ann Intern Med 200I, I 35(II):982-989.

18. Ray WA: Learning from aprotinin - mandatory trials of comparative efficacy and safety needed. N Engl J Med 2008, 358(8):840-842.

19. Brown JR, Birkmeyer NJ, O'Connor GT: Meta-analysis comparing the effectiveness and adverse outcomes of antifibrinolytic agents in cardiac surgery. Circulation 2007, I I 5(22):280 I-28I3.

20. Henry DA, Carless P, Fergusson D, Laupacis A: The safety of aprotinin and lysine-derived antifibrinolytic drugs in cardiac surgery: a meta-analysis. CMAJ 2009, 180(2):

21. Gagne JJ, Griesdale DEG, Schneeweiss S: Death and Renal Dysfunction with Aprotinin Use in Cardiac Surgery: A MetaAnalysis of Observational Studies. In 24th International Conference on Pharmacoepidemiology \& Therapeutic Risk Management Copenhagen, Denmark; 2008.
22. Ray WA, Stein CM: The aprotinin story - Is BART the final chapter? N Engl J Med 2008, 358:2398-400.

23. Shea BJ, Grimshaw JM, Wells GA, Boers M, Andersson N, Hamel C, Porter AC, Tugwell P, Moher D, Bouter LM: Development of AMSTAR: a measurement tool to assess the methodological quality of systematic reviews. BMC Med Res Methodol 2007, 7:10.

\section{Pre-publication history}

The pre-publication history for this paper can be accessed here:

http://www.biomedcentral.com/1472-6963/9/34/prepub
Publish with Biomed Central and every scientist can read your work free of charge

"BioMed Central will be the most significant development for disseminating the results of biomedical research in our lifetime. "

Sir Paul Nurse, Cancer Research UK

Your research papers will be:

- available free of charge to the entire biomedical community

- peer reviewed and published immediately upon acceptance

- cited in PubMed and archived on PubMed Central

- yours - you keep the copyright
BioMedcentral 